\title{
Bolivianos em São Paulo: entre o sonho e a realidade
}

\author{
SIDNEY ANTONIO DA SILVA
}

\section{Introdução}

$\mathrm{E}$

M JANEIRO de 1951, Mario, oriundo de Cochabamba - cidade situada na região central da Bolívia -, desembarcava em Corumbá (MS), depois de uma longa viagem feita pelo trem que liga a cidade de Santa Cruz de la Sierra à fronteira brasileira, para depois seguir em direção ao seu destino final, a cidade do Rio de Janeiro. Lá ele se empenharia em conquistar o seu sonho, isto é, estudar engenharia mecânica pelo programa de intercâmbio cultural Brasil-Bolívia.

Cinqüenta e quatro anos depois, no mês de maio de 2005, René, natural de La Paz - cidade do altiplano boliviano -, também escolheria o Brasil para morar e trabalhar, porém desembarcando na cidade que aglutina o maior contingente de imigrantes bolivianos no país, São Paulo. É nessa metrópole que ele tenta realizar o seu sonho: ter seu próprio negócio, isto é, uma oficina de costura. Embora ambos tenham vindo ao Brasil em épocas diferentes e tenham sido motivados por objetivos distintos, algo eles têm em comum, o sonho de uma vida melhor, que a sua pátria não podia lhes oferecer.

Este artigo tem como objetivo analisar o processo de inserção dos imigrantes bolivianos em São Paulo, focando as dificuldades enfrentadas por eles em suas trajetórias na cidade, bem como as estratégias de mobilidade e de reconhecimento social, as quais vão sendo construídas num contexto adverso, marcado tanto pela indocumentação quanto pela discriminação racial e social.

\section{O El Dorado é aqui? O Brasil no imaginário dos imigrantes}

Quem migra leva consigo sonhos de uma vida melhor para si e suas famílias, de obter sucesso econômico rápido e de regressar vitorioso, o quanto antes, à sua terra natal, pois o retorno é, segundo Sayad (2000), um elemento constitutivo da condição do imigrante. Entretanto, a decisão de emigrar está sempre ancorada em idéias positivas que são construídas sobre o lugar de destino, as quais são veiculadas, em geral, pela imprensa, ou ainda pelos agenciadores de imigrantes no local de partida. Entre as imagens mais recorrentes, temos aquelas que já fazem parte de um imaginário mais amplo, presente entre os hispano-americanos, que vêem o Brasil como o país do futebol, do samba, de belas praias, de natureza exuberante, das mulatas, das oportunidades de emprego, entre outras.

Para Le Goff (1994, p.12), o imaginário não se reduz à idéia de representação, mas “embora ocupando apenas uma fração do território da representação, 
vai mais além dele. A fantasia - no sentido próprio da palavra - arrasta o imaginário para lá da representação, que é apenas intelectual". Em outras palavras, o imaginário é o modo pelo qual os historiadores lidam com uma certa dimensão cultural da história, para dar conta de idéias e representações que, traduzindo-se em imagens, não são explicáveis em termos de uma história événementielle ou conjuntural, porque remetem a conteúdos culturais de uma outra natureza.

A explicação da imagem do Brasil como um lugar exótico, por um lado, e cheio de oportunidades, por outro, deve ser buscada, entretanto, no imaginário europeu que perseguiu os colonizadores desde o princípio da aventura da conquista das terras americanas, pois para eles teria existido um lugar, denominado de El dorado, onde haveria muitas riquezas, sobretudo o ouro, objeto primeiro do desejo que estimulou os empreendimentos da conquista. Tal figura passou por transformações ao longo do século XVI. Da imagem de um homem coberto de ouro, donde seu nome de El Dorado, ou "Príncipe Dourado", passou a ser visto-imaginado como um reino, cuja capital, Manoa, se situaria às margens de um lago salgado. Naturalmente, um tal reino não poderia ter um lugar fixo, ora sendo localizado em Nova Granada ora na Venezuela, ora em algum ponto do Rio Amazonas, ou ainda nas Guianas (Ramos apud Ugarte, 2003, p.288), embora seja certo que foram inúmeras as expedições que buscaram, sem sucesso, encontrá-lo, num ou noutro desses lugares.

Séculos depois da conquista, precisamente a partir da segunda metade do século XIX, milhões de europeus deixavam a suas terras em busca de uma outra, onde o sonho da abundância e da riqueza pudesse tornar-se realidade. Tal sonho foi traduzido na conhecida expressão: Fare l'América, ou em outros termos, o El Dorado americano. Hoje a história se repete de forma inversa, pois descendentes de italianos, japoneses, espanhóis, alemães, entre outros, fazem a caminho de volta para a terra de onde vieram seus antepassados. Se para muitos brasileiros o Brasil já não é mais o país das oportunidades, para os bolivianos(as), ele continua sendo. Essa é a razão pela qual milhares deles deixam a Bolívia anualmente, para fugir da pobreza e de uma economia de subsistência e, assim, vislumbrar, alguma possibilidade de mobilidade social. ${ }^{1}$ É o que afirma Benigno, 28 anos, casado, com dois filhos, natural da província de Camacho, La Paz, onde trabalhava como camponês: "trabajaba solo para mi alimentación, non tenia terreno grande. Somos seis hermanos, no tenia un campo para mi. Yo soy el mayor, por eso be decidido venir a este lado". A motivação de Benigno para emigrar é semelhante à de tantos outros bolivianos(as) que partiram em busca de um emprego, de uma possibilidade que viabilizasse seus projetos de vida.

As promessas de boas oportunidades se transformam, entretanto, por vezes, em frustração e humilhação. Foi o que aconteceu com Davi, 26 anos, grau de escolaridade média, natural da Ciudad Del Alto, La Paz, onde trabalhava numa fábrica de bebidas. Ele veio ao Brasil em 2005, com mais três bolivianos, trazido por um agenciador de mão-de-obra residente na sua cidade, o qual cobrou US\$ 400 de cada um deles pela viagem. Davi afirma que veio iludido com 
a promessa de que, em São Paulo, era possível ganhar muito dinheiro, de que o empregador lhes daria casa, comida, diversão nos fins de semana.

Quando, porém, chegou a São Paulo, a realidade era outra. Trabalhavam das seis da manhã até meia-noite, alimentando-se mal. O patrão, um boliviano, não os deixava sair, intimidando-os, dizendo que a Federal (polícia) estaria rondando por ali e poderia detê-los. O tempo de reclusão, para indocumentados, segundo ele, seria de quinze anos. Trabalhou cinco meses com esse boliviano e não recebeu nada. Segundo o oficinista, o dinheiro era enviado à Bolívia para os seus familiares, o que não era verdade. Saiu num sábado e viu outros bolivianos e perguntou onde precisava de costureiro e começou a trabalhar para outro boliviano.

A história de Davi revela que as expectativas alimentadas ao longo da travessia se diluem tão logo aparece a mão ambiciosa de alguns oficinistas, sejam eles bolivianos ou não, que agem sem escrúpulos e à revelia das leis vigentes no país, quando está em jogo o seu projeto de mobilidade econômica a qualquer preço. Vale notar, contudo, que, nesse contexto, a sujeição de um trabalhador a um empregador não se dá sem a sua conivência, pois para ele as relações de exploração desenvolvidas nas oficinas de costura são vistas como um momento transitório em vista de uma situação posterior

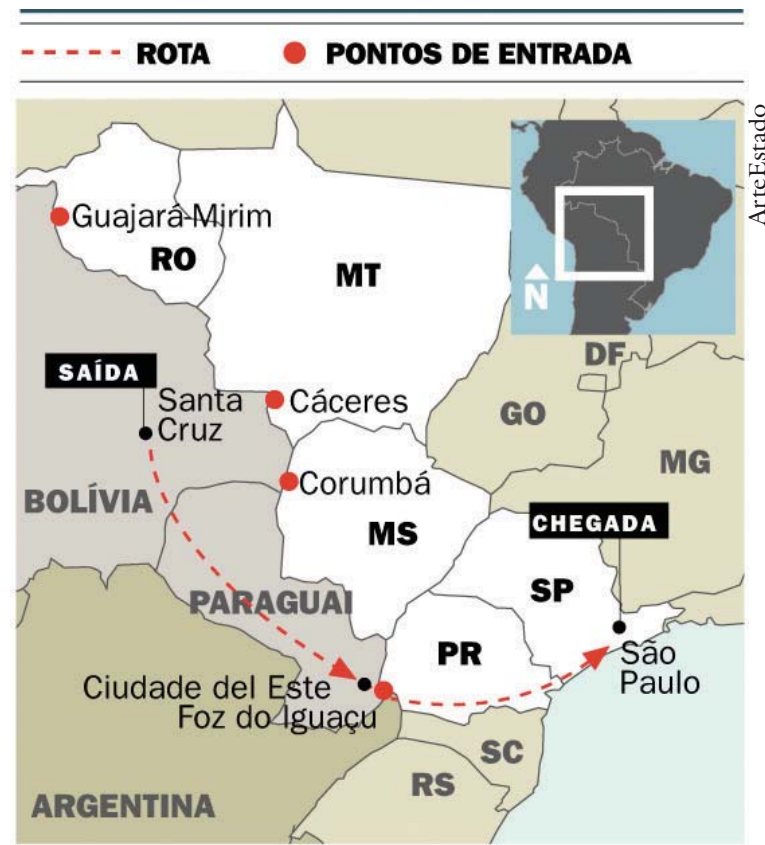

Rota e pontos de entrada de bolivianos no Brasil. diferenciada, a qual resultaria numa mudança de papéis, isto é, o trabalhador passaria da condição de costureiro para a de oficinista. Esse é o sonho acalentado pela maioria dos que trabalham nesse segmento do mercado de trabalho paulistano. Mas como é possível realizar tal sonho? Quais são os desafios que terão que enfrentar? É o que trataremos de mostrar ao longo deste texto.

\section{Os imigrantes bolivianos em São Paulo: perfil e problemática}

A presença boliviana em São Paulo não constitui um fato novo. Embora ela tenha se tornado significativa somente a partir da década de 1980, pode-se dizer, contudo, que tal presença remonta ao início da década de 1950, quando já era possível constatar alguns bolivianos na cidade na condição de estudantes, os quais vieram estimulados pelo programa de intercâmbio cultural Brasil-Bolívia. Após o término dos estudos, muitos deles acabavam optando pela sua permanência na cidade, em razão das múltiplas ofertas de emprego encontradas naquele momento no mercado de trabalho paulistano (Silva, 1997, p.82). 
As razões pelas quais os bolivianos continuam deixando a Bolívia são múltiplas. Porém, os fatores de ordem econômica são preponderantes na decisão de emigrar, já que o mercado de trabalho brasileiro, mesmo na denominada "década perdida", ou seja, a de 1980, oferecia mais oportunidades de emprego do que o mercado de trabalho boliviano, já que o país enfrentava uma profunda crise econômica, com altos índices de inflação e desemprego.

O perfil característico desses imigrantes, que foi sendo construído desde os anos 1980, mostra que eles são, em sua maioria, jovens, de ambos os sexos, solteiros, de escolaridade média, e vieram atraídos principalmente pelas promessas de bons salários feitas pelos empregadores coreanos, bolivianos ou brasileiros da indústria da confecção. Oriundos de várias partes da Bolívia, porém com uma predominância dos pacenhos e cochabambinos (isto é, provenientes de La Paz e Cochabamba, respectivamente), esses imigrantes passaram a apostar tudo na atividade da costura, alimentando, assim, sonhos de uma vida melhor para si mesmos e seus familiares que lá ficaram.

À medida que eles vão se estabelecendo na cidade, inicia-se um processo de reunificação familiar, com a vinda de irmãos, parentes e pais, muitas vezes pessoas oriundas do campo e com pouco domínio do espanhol. Em São Paulo, os mais idosos são incorporados de alguma forma ao processo de produção nas oficinas de costura, exercendo atividades suplementares, como é o caso das mulheres que preparam a comida servida aos trabalhadores.

Hoje, a presença boliviana é um fato consolidado na cidade de São Paulo, seja pela manutenção do fluxo migratório ao longo da década de 1990, tornando-se o grupo mais numeroso entre os hispano-americanos que vivem na cidade, seja pelo fato de que novas famílias começaram a se formar em São Paulo, em geral de forma endogâmica. Outro elemento balizador desse processo migratório na cidade é a existência de várias organizações socioculturais criadas por eles nos últimos anos. Entre elas, destacam-se a Associação dos Residentes Bolivianos e o Círculo Boliviano, as mais antigas na cidade, a Associação Interligas, que reúne times de futebol, as várias Fraternidades Folclóricas, a Associação Bolívia/Brasil, que defende os interesses dos oficinistas, a Associação Gastronômica Praça Kantuta, entre outras.

Do ponto de vista espacial, os bolivianos(as) estão concentrados em bairros da Zona Central da cidade, como Bom Retiro, Brás, Pari, Barra Funda, Cambuci, Mooca, entre outros. Entretanto, há também uma significativa presença deles em bairros da Zona Leste, como Belém, Tatuapé, Penha, Itaquera, Cangaíba, Engenheiro Goulart, Ermelino Matarazzo, Guaianases, São Mateus, e em bairros da Zona Norte, como Vila Maria, Vila Guilherme, Casa Verde, Cachoeirinha, entre outros. Entretanto, nos últimos anos, a presença de bolivianos extrapolou os limites do município de São Paulo, podendo ser encontrada em cidades como Guarulhos, Osasco, Santo André, Diadema, e em outras cidades do interior paulista, como Jundiaí, Campinas, Americana, entre outras. 


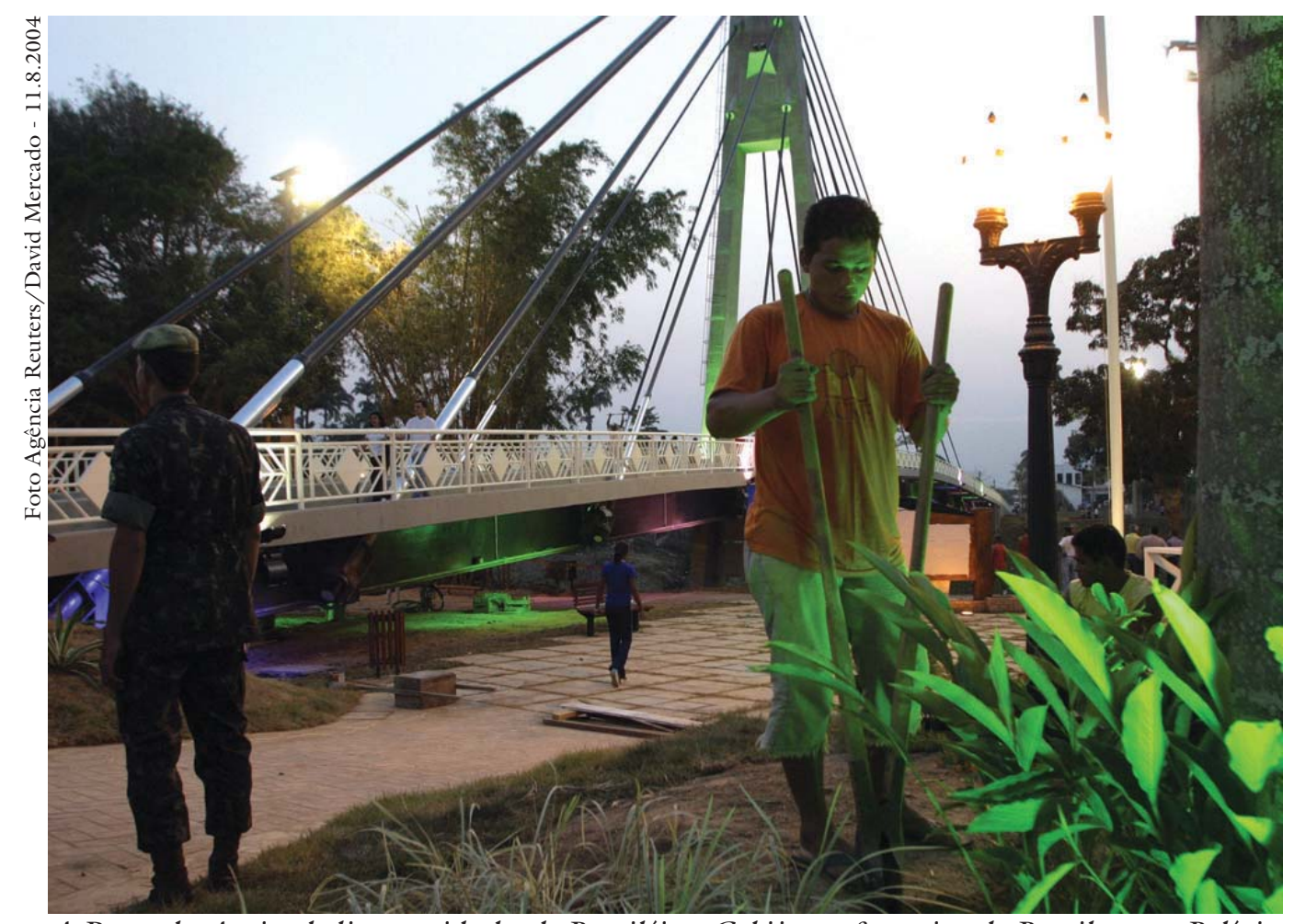

A Ponte da Amizade liga as cidades de Brasiléia e Cobija na fronteira do Brasil com a Bolínia.

Do ponto de vista ocupacional, os bolivianos que entraram no país, a partir da década de 1980, trabalham, em sua maioria, no setor da costura, por ser esse um segmento do mercado de trabalho que não exige experiência prévia nem idade mínima para o trabalho, incorporando mesmo menores. Do trabalhador se exige apenas muita coragem para se adaptar às condições insalubres de trabalho, uma vez que é um setor no qual não há nenhuma regulamentação das relações trabalhistas. Tal modo de produção se enquadra no modelo da "acumulação flexível" do capital, em que a produção se dá com base na quantidade de peças que o trabalhador é capaz de costurar.

Nesse caso, as regras de trabalho são permeadas por relações de parentesco e amizade, ensejando, assim, espaço para a subjugação dessa mão-de-obra, sobretudo das mulheres (Harvey, 1992, p.146). Em geral, eles trabalham para coreanos, brasileiros, ou mesmo para os próprios compatriotas que vão à Bolívia agenciar trabalhadores para as suas oficinas de costura. ${ }^{2} \mathrm{O}$ produto final do trabalho é vendido, em geral, nas lojas da cidade, algumas delas muito conhecidas no comércio local.

Além da atividade da costura, vale destacar um significativo grupo de profissionais liberais, entre eles, médicos e dentistas, os quais, além de enfrentarem o problema da regularização no país, são desafiados também pela dificuldade da revalidação dos seus títulos acadêmicos, cujo processo é lento e dispendioso. A área de serviços e do comércio ambulante é outro setor que absorve parte dessa mão-de-obra boliviana que chega a São Paulo, em geral indocumentada. 
O problema da indocumentação tem sido um dos grandes desafios para os imigrantes mais pobres no Brasil, particularmente para os bolivianos(as), uma vez que o Estatuto do Estrangeiro, aprovado em 1980 por decurso de prazo e num contexto de Segurança Nacional, só permite a entrada de mão-de-obra especializada e de empreendedores no país. Para os que não se enquadram nesses critérios, as duas únicas possibilidades de regularização são o casamento com cônjuge brasileiro ou o nascimento de um filho em território brasileiro. Entretanto, por falta de informação, há casos em que bolivianas acabam registrando seus filhos nascidos no Brasil no nome de uma irmã que já esteja documentada no país. A razão para tal atitude é o temor de serem descobertas pela Polícia Federal, por não estarem regularizadas no país. O problema é reverter essa situação, depois que elas conquistam a própria documentação. Em outros casos, as crianças não são registradas porque os pais acreditam que no registro constará apenas o nome da mãe, em razão da sua condição de indocumentados.

No início de setembro de 2005, o Ministério da Justiça lançou um anteprojeto de lei para ser debatido pela sociedade brasileira, num exíguo prazo de trinta dias. A nova proposta de lei dos estrangeiros provocou reações contrárias à sua aprovação, sobretudo das organizações não-governamentais que atuam junto aos imigrantes, uma vez que, em alguns aspectos, o anteprojeto significa um retrocesso em relação à atual lei vigente no país. Diante das reações negativas da sociedade civil, o governo resolveu apresentar uma nova proposta para ser discutida, porém essa ainda não veio a público. As considerações aqui expressas foram feitas, portanto, a partir do texto do anteprojeto apresentado naquela ocasião.

Embora no artigo $3^{\mathrm{o}}$ sejam ressaltados os princípios que deverão nortear a nova lei, entre eles a "política nacional de imigração", a questão dos "direitos da pessoa humana", e pelos direitos e garantias fundamentais consagrados na Constituição brasileira, vale notar que no decorrer do texto tais princípios acabam esquecidos e subordinados à lógica da "segurança nacional". Aliás, vale notar que a questão da criminalização das migrações é um fato cada vez mais recorrente no contexto internacional, particularmente nos Estados Unidos, onde o imigrante indocumentado é visto como um criminoso, por ter entrado ilegalmente no país ou nele permanecer além do tempo permitido pela lei (Póvoa Neto, 2005, p.297).

Entres os pontos mais polêmicos, destaca-se a limitação dos direitos de expressão e de participação política dos estrangeiros no Brasil. Quanto ao primeiro, o artigo 116, inciso III, veta ao estrangeiro "ser responsável, orientador intelectual ou administrativo" de qualquer empresa relacionada aos meios de comunicação social. Já no artigo 117, o anteprojeto proíbe o estrangeiro de organizar, criar ou manter sociedade ou quaisquer entidades de caráter político, ainda que tenham por fim apenas a propaganda ou a difusão, exclusivamente entre compatriotas, de idéias, programas ou normas de ação de partidos políticos do país de origem; promover ou participar de atividades hostis a governos estrangeiros; organizar desfiles, passeatas, comícios e reuniões de qualquer natureza, ou deles participar. 
O artigo limita de forma cabal os direitos de expressão e de participação política, direitos esses já concedidos a estrangeiros em outros contextos, como é o caso de vários países europeus, ou ainda da vizinha Argentina, que reconhecem o direito ao voto, pelo menos em nível municipal.

Além dessas limitações, outras são encontradas ao longo do texto, como no artigo 119, inciso III: o anteprojeto exige como requisito para a concessão da naturalização a "residência contínua no território nacional, pelo prazo mínimo de dez anos, imediatamente anteriores ao pedido de naturalização", e na lei atual, 6.815/80, o requisito é de quatro anos. Outra restrição é a encontrada no artigo 28 , que torna extensivo a todo grupo familiar o impedimento de entrada no país de algum de seus integrantes, responsabilizando, assim, a todos pelos atos de uma única pessoa.

O mais grave ainda é a proposta do artigo 138, que abre a possibilidade da denúncia por interesse de quem tenha sido vítima do tráfico ilícito de imigrantes e esteja de forma irregular no Brasil, isentando-o das responsabilidades administrativas sobre seus atos. O problema é que tal medida pode criar uma onda de denuncismo, vindo a prejudicar, eventualmente, pessoas que sempre trabalharam de forma honesta no país.

Em geral, o anteprojeto mantém o caráter incriminador e seletivo presente no Estatuto do Estrangeiro vigente no país, pois privilegia trabalhadores qualificados nas mais diferentes áreas do conhecimento, excluindo, dessa forma, aqueles que vêm atender à demanda de mão-de-obra em setores que não exigem uma alta qualificação, como é o caso dos setores de confecções e de serviços. Tal enfoque, entretanto, não é uma exceção, pois as legislações migratórias em discussão em outros contextos caminham nessa direção. Entre os pontos positivos do anteprojeto, vale notar, contudo, a ampliação dos vistos temporários para ONG e voluntários, que queiram vir ao Brasil realizar alguma ação humanitária, bem como o estímulo aos acordos bilaterais dentro do contexto do Mercosul.

Nessa perspectiva, no dia 15 de agosto de 2005 foi assinado um acordo entre Brasil e Bolívia para a regularização dos indocumentados em ambos os países. As estimativas do Ministério da Justiça eram de que havia sessenta mil bolivianos irregulares no Estado de São Paulo ( O Estado de S. Paulo, 12.3.2006). O problema, porém, é a pesada multa que cada imigrante terá que pagar para regularizar-se, a qual gira em torno de $\mathrm{R} \$ 828,00$, valor equivalente a cem dias de ilegalidade no país. Somados a multa e os gastos com taxas que o imigrante terá que pagar aos cofres públicos, o custo final do documento fica em torno de mil reais por pessoa.

Na Argentina, por exemplo, a regularização não tem nenhum ônus para o requerente, pelo menos nos dois primeiros anos, e o processo de documentação é menos burocrático. Apesar de todas essas dificuldades para regularizar-se, cerca de dez mil bolivianos haviam entrado com o pedido de permanência em São Paulo, até meados de abril de 2006. Cerca de sete mil com base no acordo bilateral Brasil-Bolívia, e mais de dois mil, com base em filho brasileiro, como prevê o atual Estatuto do Estrangeiro. 


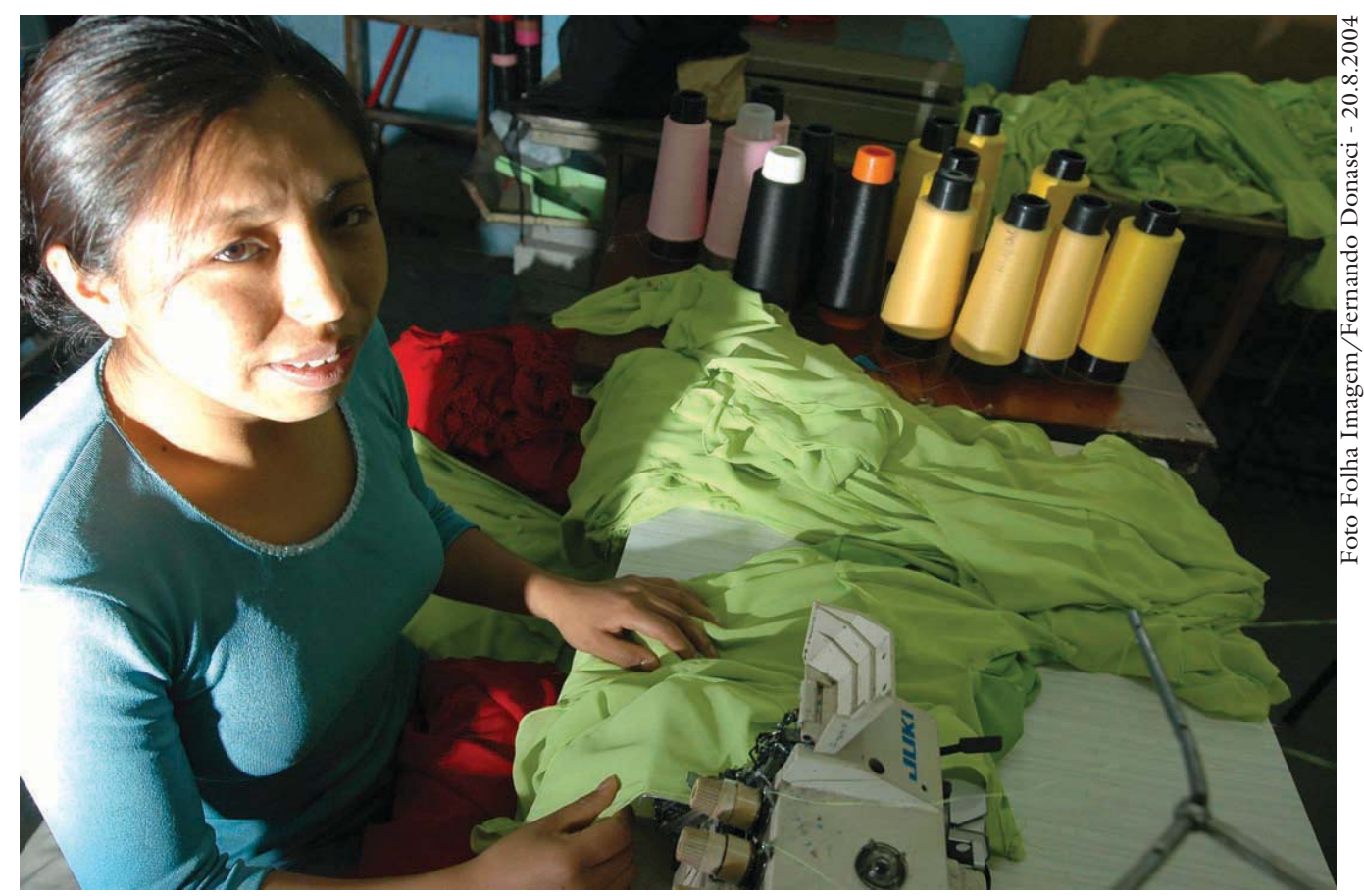

A boliviana Francy Apaza em oficina de costura no bairro do Bom Retiro, em São Paulo.

Estar regularizado no país é, nesse contexto, uma condição sine qua non para os que acalentam o sonho de ter a sua própria oficina de costura, pois sem documento não é possível abrir uma firma, uma conta bancária, fazer um crediário etc. Para os trabalhadores, entretanto, o documento não significa necessariamente direitos assegurados, uma vez que seus patrões não os registram após a sua obtenção. Se eles quiserem continuar trabalhando, deverão sujeitar-se, portanto, às regras impostas por esse setor do mercado de trabalho, cuja marca preponderante é a circularidade da mão-de-obra e a desregulamentação das relações de trabalho. É nesse contexto que são tecidas algumas estratégias de mobilidade econômica e social, como veremos em seguida.

\section{Costurando estratégias de mobilidade econômica e de reconhecimento social}

Se o que define o imigrante é a sua condição de trabalhador temporário, como afirma Sayad (1998), poderíamos nos perguntar se tal condição mudaria à medida que ele começa a estabelecer relações duradouras com o novo contexto que escolheu para viver e trabalhar. Estudos de grupos de migrantes que ainda estão na primeira geração, como é o caso dos brasileiros nos Estados Unidos (Sales, 1999), mostram que a redefinição da expectativa temporal resulta na elaboração de um outro projeto de vida, no qual o imigrante começa a admitir a possibilidade de lá permanecer por um tempo mais longo. Embora essa seja uma decisão de cada imigrante, tais expectativas são partilhadas, contudo, pelo grupo como um todo, pois a idéia de que as condições para o retorno ainda não estão consolidadas passa a ser compartilhada por todos. Nessa perspectiva, o retorno é 


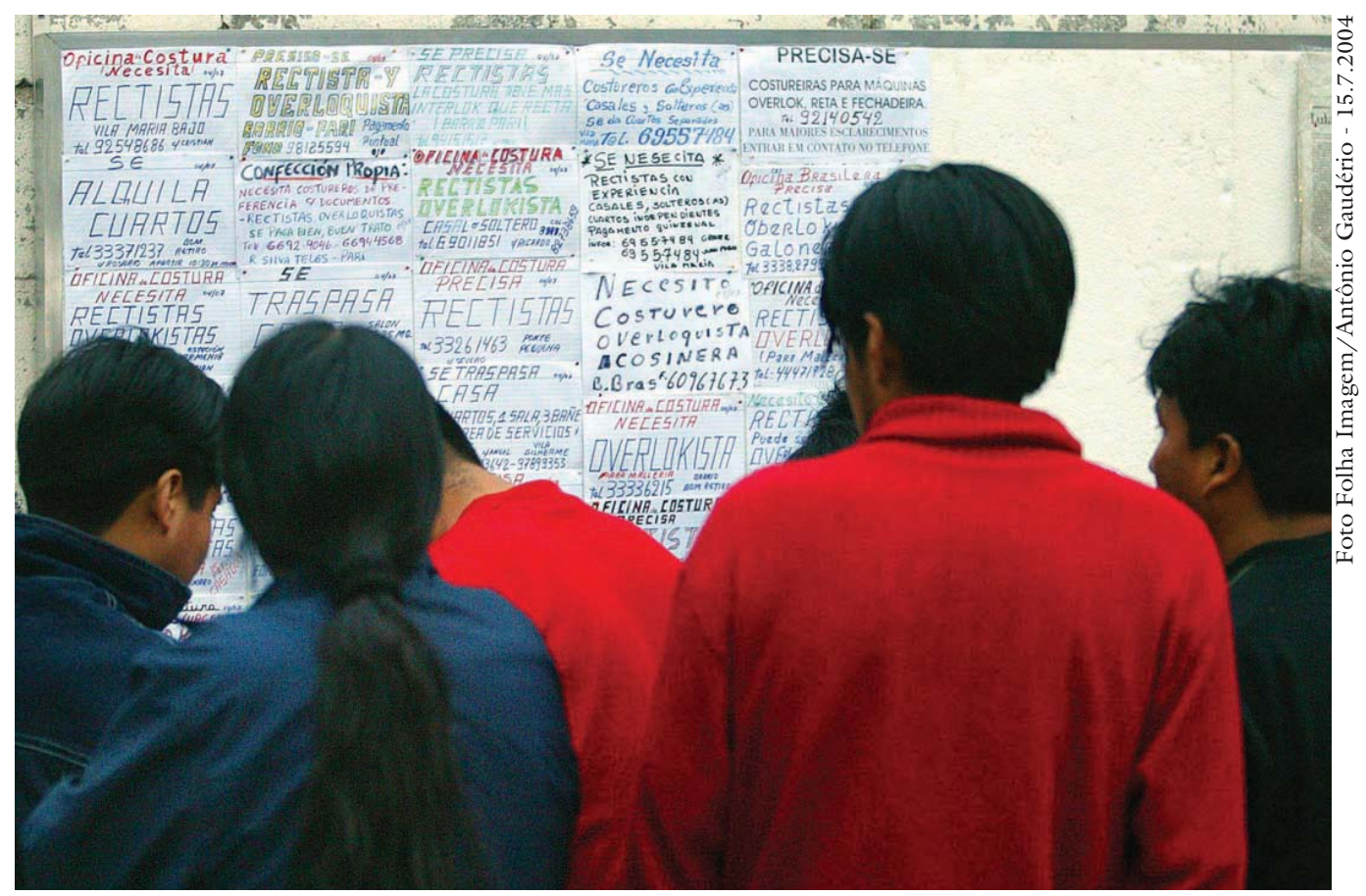

Jovens bolivianos observam mural de anúncios de emprego na Praça Kantuta, em São Paulo.

transferido para uma outra fase da vida, como a aposentadoria, os filhos criados (ibidem, p.132).

No caso que estamos focando, o que se verifica é que existe uma diferenciação de expectativas entre aqueles que estão há mais tempo no país e, portanto, com uma situação financeira relativamente definida, e aqueles que chegaram recentemente. Para os primeiros, o projeto do retorno é uma possibilidade que não foi descartada totalmente, porém já não se coloca mais como algo a ser buscado em curto prazo, em razão dos laços que foram criados com o Brasil, seja do ponto de vista econômico, cultural, seja afetivo. A volta se dá, portanto, de forma intermitente, para visitar os parentes, para matar a saudade da terra natal e de seus sabores, e regressar em seguida, pois lá se sentiriam como "peixes fora d'água". Outra forma de se realizar esse retorno, ainda que de forma simbólica, é mandar um dos filhos para estudar na Bolívia. Assim, por intermédio da segunda geração, se manteriam os vínculos com a terra natal.

Para os recém-chegados, o projeto do retorno é algo que se coloca de forma mais objetiva, pois a razão de sua emigração é a conquista de recursos, para, no retorno, realizar o seu sonho de independência econômica. Entretanto, dada a falta de oportunidades e das exíguas chances de mobilidade social no país de origem, os imigrantes que trabalham no ramo da costura passam a apostar tudo na conquista de sua própria oficina de costura, cujo processo de produção se dá mediante a conjugação do trabalho familiar e da contratação de compatriotas. Esses trabalham no regime de produção por peças costuradas, exigindo dos trabalhadores uma dupla jornada de trabalho para se ganhar um pouco mais (Silva, 1997, p.127). 
Em geral, o oficinista que foi à Bolívia buscar seus trabalhadores oferecelhes casa e comida, propiciando, assim, a emergência de relações de dependência de um para com o outro, em razão de um "favor" que o empregador fez para com seus empregados. Esses, por sua vez, deverão trabalhar para ele, pelo menos por um ano. ${ }^{3}$ Os rendimentos de cada trabalhador dependem de suas habilidades em aprender rapidamente os macetes da costura, o que representa um grande desafio para quem nunca viu uma máquina de costura em sua vida, como é o caso de camponeses e jovens, que no país de origem apenas estudavam. $\mathrm{Na}$ fase inicial de aprendizado, os rendimentos variam de $\mathrm{R} \$ 150$ a $\mathrm{R} \$ 200$. Porém, à medida que os costureiros adquirem a habilidade da costura, os rendimentos podem melhorar, sobretudo em épocas de intensa demanda, como é o período que antecede o Natal.

Apesar dos baixos rendimentos, a maioria deles consegue enviar algum dinheiro aos seus familiares, cerca de US\$ 100, pelo menos a cada dois ou três meses. Tais remessas são feitas por intermédio de amigos que viajam à Bolívia, ou de agências que cobram $5 \%$ sobre o montante enviado.

Vale dizer, contudo, que para os mais jovens o trabalho da costura é visto como algo transitório, pois grande parte deles alimenta o sonho de estudar e, assim, poder mudar de profissão num futuro não tão distante, ou simplesmente voltar a exercer a atividade que realizava na Bolívia, antes de emigrar. Para isso, ele terá que estar regularizado no país. Contudo, para esses jovens, o grande desafio é conciliar as exigências do trabalho na oficina de costura com os horários de estudo.

É importante ressaltar ainda que os oficinistas já estabelecidos na cidade procuram conjugar o trabalho da costura como outras atividades econômicas, como é o caso dos bares e restaurantes, serviço de telefonia e transporte, ou ainda a venda de produtos típicos. Esses são vendidos em pequenos negócios localizados nos bairros do Brás e do Pari, ou ainda nas feiras livres realizadas nos fins de semana, como é o caso da que acontece todos os domingos na Praça Kantuta, no bairro do Canindé.

Se a mobilidade econômica é possível mediante a combinação de estratégias já apontadas anteriormente, o mesmo não se pode dizer em relação ao reconhecimento social, pois esse depende da desconstrução da imagem negativa que foi se construindo ao longo dos anos 1990 sobre os bolivianos em São Paulo. Esses são associados com freqüência ao trabalho escravo e ao tráfico de mãode-obra para as oficinas de costura. Além dessa identificação negativa e que, às vezes, assume um caráter acusativo, eles têm que lidar com outros preconceitos decorrentes do desconhecimento de grande parte dos brasileiros de suas raízes étnicas e culturais. Para esses, eles são vistos como pessoas descendentes de "índios", "pobres" e de "pouca cultura".

Alguns estranhamentos já foram constatados na cidade, ainda que de forma circunstancial e localizada. Um deles foi a transferência dos bolivianos da Praça Padre Bento, no Pari, para um outro local, num bairro vizinho, o Canindé, no ano de 2002. Esse novo local foi denominado por esses imigrantes Praça 


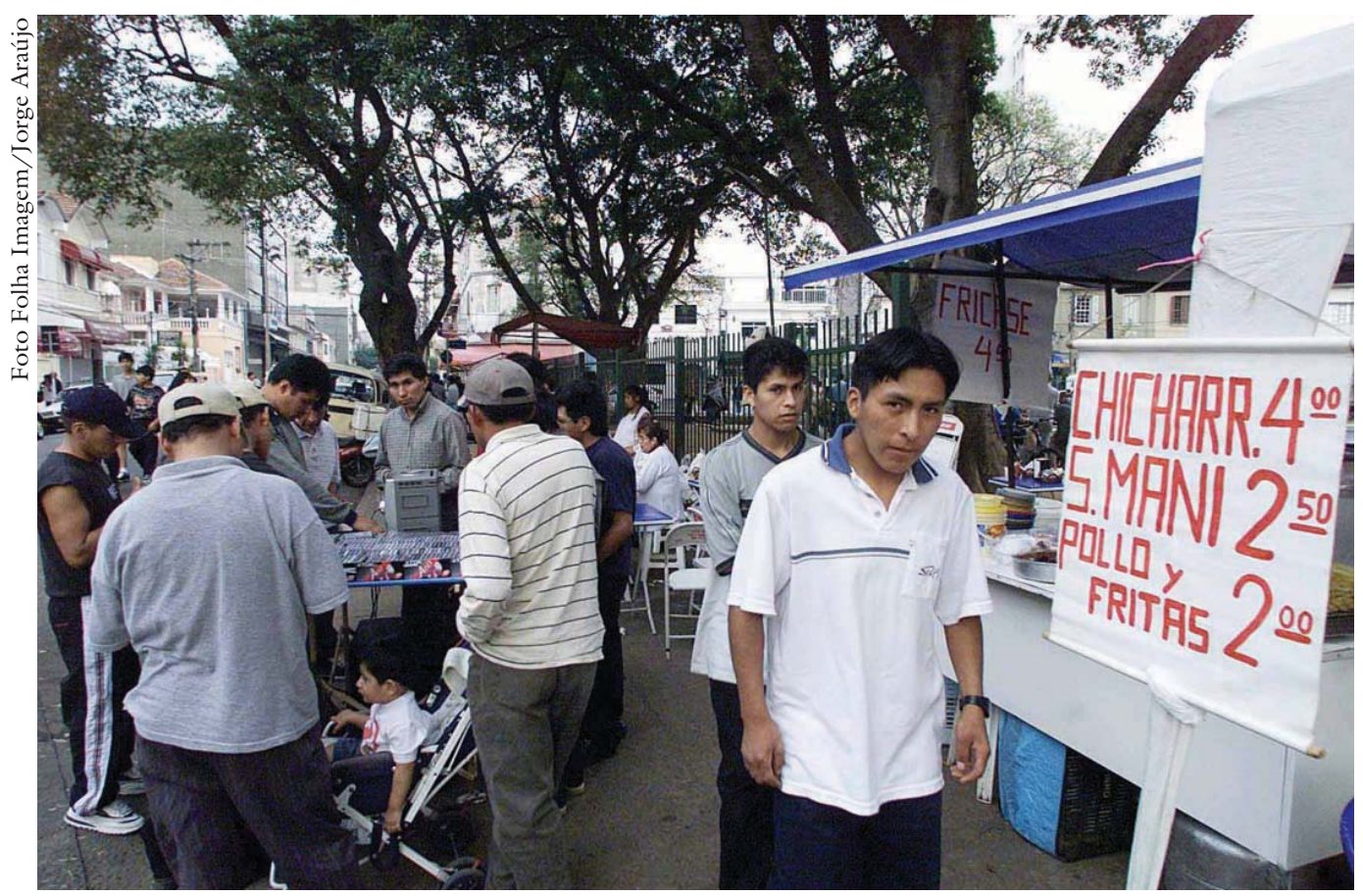

Bolivianos vendem comida e especiarias típicas de seu país no bairro do Pari, em São Paulo.

Kantuta, nome de uma flor do altiplano (Silva, 2005b). Essa praça se transforma todos os domingos num "pedaço"4 boliviano em São Paulo, pois nesse local é estabelecida uma multiplicidade de relações, sejam elas de ordem comercial, gastronômica, artística, de oferta de trabalho e de outros serviços, como corte de cabelo, fotografia, entre outros. Entretanto, essa praça tem sido o palco de atividades culturais, como o carnaval e a festa das Alasitas, ou das miniaturas.

Segundo a tradição, essa festa deve ser realizada no dia 24 de janeiro, dia em que se homenageia a deidade chamada Ekeko, ou deus da abundância. Como reza a tradição, as miniaturas de objetos que simbolizam o que se deseja alcançar devem ser adquiridas antes do meio-dia e depois deverão ser levadas ao Yative (sacerdote andino), para que esse realize o ritual da $c h^{\prime}$ alla, uma libação à Pachamama (Mãe Terra), pedindo a ela que torne o desejo, ali simbolizado na alasita, em realidade.

O problema é que o dia 24 não é feriado no Brasil, e a realização dessa festa na praça ocasiona transtornos para as pessoas que freqüentam uma escola situada em frente à referida praça. Assim, os que vivem nas proximidades da praça se sentem incomodados com a presença dos bolivianos naquele local, revelando uma vez mais a dificuldade que temos em lidar com a chegada do "estranho"; nesse caso, os (i)migrantes, ${ }^{5}$ acusados de serem portadores da desordem e da degradação urbana (Silva, 2005b, p.42).

A contrapartida desse processo de discriminação se dá pela mobilização do grupo em torno de práticas culturais veiculadas, particularmente nas festas devocionais realizadas em São Paulo, em louvor a Nossa Senhora de Copacabana. 
Tais festas são por eles realizadas anualmente no mês de agosto, num contexto específico, que é o espaço cedido pela Igreja Católica. Importa lembrar, porém, que, até 1994, tais festas eram realizadas como celebrações privadas, envolvendo apenas os devotos e compatriotas, em geral do mesmo lugar de origem da devoção, como é o caso dos pacenhos (Departamento de La Paz). A partir daquela data, a festa que comemora a padroeira boliviana passou a ser realizada na Igreja Nossa Senhora da Paz, localizada na região central da cidade de São Paulo. Nesse local funciona a sede da Pastoral do Migrante, que reúne também imigrantes de outras nacionalidades.

A realização de práticas festivas nesse espaço eclesial confere-lhe, portanto, significados específicos, a partir de uma lógica que opera com muitos eixos de significação, construídos por pares de contrastes: imigrante/nacionais; boliviano/brasileiro; boliviano/peruano; sagrado/profano; católico/andino; costureiros/profissionais, e assim por diante. Tais práticas, além de outras que são realizadas por esses imigrantes durante o ano naquela igreja, conferem a esse espaço a característica de um "pedaço" boliviano em São Paulo, lugar onde, à semelhança de outros na cidade, se estabelece uma multiplicidade de relações, tecendo, assim, redes de sociabilidades (Magnani \& Torres, 1996, p. 40).

Nessa perspectiva, a festa apresenta-se como uma mediação no processo de negociação de uma identidade positiva no âmbito da sociedade local, inclusive permitindo a esses imigrantes negociar outros espaços de inserção na metrópole, como é o caso do Memorial da América Latina e da quadra da Escola de Samba Camisa 12, local onde se realiza a celebração do último dia dos festejos.

As práticas festivas realizadas por esses imigrantes na cidade revelam, portanto, a vitalidade cultural de um grupo que, apesar da conjuntura adversa em que está inserido, procura mostrar que eles têm algo a mais para oferecer à sociedade paulistana, além de sua mão-de-obra mal paga nas oficinas de costura. Um exemplo disso são as fraternidades folclóricas que foram criadas nos últimos anos na cidade, com o objetivo de animar as festas devocionais. Uma delas é a Fraternidad Morenada Bolívia Central, fundada em 2002, a qual reúne pelo menos trezentos integrantes, a maior parte deles donos de oficinas de costura. Todos os anos novas roupas e alegorias usadas pelos morenos e cholitas que participam da dança são alugadas e trazidas da Bolívia, a um custo de US\$ 100, cada uma.

Esse exemplo nos permite dizer que, embora haja pessoas que se sintam incomodadas com a presença desses imigrantes na cidade, preferindo vê-los longe de suas praças, a presença boliviana é hoje um fato consolidado na metrópole paulistana, e, como tal, ela contribui para tornar esta "Paulicéia desvairada" cada vez mais dinâmica e plural.

Notas

1 No dia 12 de março de 2006, o jornal O Estado de S. Paulo publicou uma matéria intitulada: "Brasil, a América dos bolivianos". Nela, a jornalista Luciana Garbin aborda 
as estratégias e as rotas de entrada no Brasil, as imagens que os bolivianos têm sobre o país, bem como os meandros da clandestinidade na cidade de São Paulo.

2 Vale notar que existem redes de agenciamento de mão-de-obra na Bolívia, em cidades como La Paz, de onde vem grande parte dos bolivianos que vivem em São Paulo, e Santa Cruz de La Sierra, cidade mais próxima do Brasil e, portanto, última etapa antes da saída do país. O custo da viagem para o emigrante pode variar, dependendo do trajeto escolhido. Para quem opta pela entrada por Corumbá (MT), pode custar cerca de US\$ 120. Porém, o risco de ser detido por um agente federal é maior. Já quem escolhe a rota do Paraguai terá que enfrentar uma longa e exaustiva viagem até chegar à Ciudad del Leste, para depois cruzar a fronteira e entrar no Brasil por Foz do Iguaçu (PR). O custo desse trajeto pode chegar a US\$ 160.

3 As relações de trabalho são rompidas, em geral, quando o empregador não cumpre as promessas feitas aos costureiros, particularmente não lhes pagando os seus salários durantes vários meses. Nesse caso, a única saída é buscar ajuda em alguma instituição, entre elas a Pastoral do Migrante. Em alguns casos, a exploração chega ao seu limite, transformando-os em escravos. O esquema de subjugação imposto pelos oficinistas consiste na retenção dos seus documentos, na proibição de sair nos fins de semana e no exaustivo regime de trabalho imposto aos trabalhadores(as). Segundo a Pastoral do Migrante, o número de mulheres em condições servis tem aumentado nos últimos anos nas oficinas de costura, incluindo os casos de violência física contra elas.

4 A Rua Coimbra, no bairro do Brás, é outro exemplo dessa forma de apropriação do espaço urbano. Nela, a partir do meio-dia de sábado, os bolivianos se aglutinam em busca de entretenimento, produtos e comidas típicas, de serviços, como cabeleireiros, passagens áreas, ligações telefônicas para o país de origem etc.

5 A presença de albergues municipais na região do Pari tem permitido a associação dos migrantes com as mudanças pelas quais o bairro vem passando, e, portanto, eles têm sido responsabilizados pela sua degradação. Segundo alguns moradores, a região deixou de ser um "lugar tranqüilo e familiar", razão pela qual alguns moradores estariam se mudando para outro bairro vizinho. Entre os bolivianos em São Paulo, particularmente entre os costureiros, há um temor de que a crise política entre a Bolívia e o Brasil, deflagrada pela nacionalização do gás naquele país, possa contribuir para exacerbar ainda mais a discriminação de alguns setores da sociedade brasileira em relação a eles. Mensagens ofensivas e arrogantes alusivas ao fato veiculadas na internet parecem confirmar tal temor.

Referências bibliográficas

HARVEY, D. Condição pós-moderna. São Paulo: Loyola, 1992.

FRUGOLI JUNIOR, H São Paulo: espaços públicos e integração social. São Paulo: Marco Zero, 1995

LE GOFF, J. O imaginário medieval. Lisboa: Estampa, 1994.

MAGNANI, J. G. C.; TORRES, L. de L. (Org.) Na Metrópole. São Paulo: Edusp, 1996. PÓVOA NETO, H. A criminalização das migrações na nova ordem internacional. In: PÓVOA NETO, H.; FERREIRA, A. P. (Org.) Cruzando fronteiras disciplinares. Um panorama dos estudos migratórios. Rio de Janeiro: Revan, 2005. p.297-309. 
SALES, T. Brasileiros longe de casa. São Paulo: Cortez, 1999.

SAYAD, A. A imigração ou os paradoxos da alteridade. São Paulo: Edusp, 1998.

O retorno: elemento constitutivo da condição do imigrante. Travessia-Revista do Migrante, São Paulo, Centro de Estudos Migratórios, n.1, especial, janeiro 2000..

SILVA, S. A Costurando sonhos. Trajetória de um grupo de imigrantes bolivianos em São Paulo. São Paulo: Paulinas, 1997.

. Virgem/Mãe/Terra. Festas e tradições bolivianas na metrópole. São Paulo: Hucitec, Fapesp, 2003.

. Bolivianos. A presença da cultura andina. São Paulo: Lazuli, 2005a.

. A praça é nossa. Faces do preconceito num bairro paulistano. Travessia - Revista do Migrante, São Paulo, Centro de Estudos Migratórios, n.51, 2005b.

UGARTE, A. S. Margens míticas: A Amazônia no imaginário europeu do século XVI. In: DEL PRIORY, M.; GOMES, F. (Org.) Os senhores dos rios. Rio de Janeiro: Campus, 2003.

RESUMO - ESTE ARTIGO tem como objetivo analisar o processo de inserção dos imigrantes bolivianos em São Paulo, focando as dificuldades enfrentadas por eles em suas trajetórias na cidade, bem como as estratégias de mobilidade econômica e de reconhecimento social, as quais vão sendo construídas num contexto adverso, marcado tanto pela indocumentação quanto pela discriminação racial e social.

PALAVRAS-CHAVE: Bolivianos, Indocumentados, Discriminação, Identidades.

ABSTRACT - THIS PAPER aims to analyze the settlement of Bolivian immigrants in São Paulo, focusing on the difficulties they face in their trajectories in the city, as well as on their strategies for economic mobility and social recognition, which are developed in an adverse environment characterized by lack of proper documentation and by racial and social discrimination.

KEYWORDS: Bolivians, Non-documentation, Discrimination, Identities.

Sidney Antonio da Silva é antropólogo e desenvolve um projeto de pós-doutoramento no Nepo/Unicamp. @ - ssparanhos@ig.com.br

Recebido em 19.5.2006 e aceito em 22.5.2006. 